\title{
FutureJournal
}

\section{MISSÃo ORGANIZACIONAL DAS MELHORES E MAIORES EMPRESAS DO BRASIL}

Recebido: 12/03/2018

Aprovado: 07/08/2018
${ }^{1}$ Leonardo Fabris Lugoboni 2Daniel Andere de Mello ${ }^{3}$ Adalberto Americo Fischmann ${ }^{4}$ Alessandra Quishida 5 Marcus Vinicius Moreira Zittei

\section{Resumo}

A preocupação com resultados e melhores práticas faz parte do cotidiano dos gestores e das empresas; essa preocupação inclui, também, o planejamento estratégico. Nesse contexto, esta pesquisa buscou responder ao seguinte questionamento: qual a estrutura da missão organizacional das empresas classificadas como "Melhores e Maiores" no Brasil? Para isso analisamos a missão organizacional das 500 empresas mais bem classificadas pelo ranking "Melhores \& Maiores de 2012", publicado pela editora Abril. Foi possível observar que os aspectos mais presentes são a identificação de autoconceito e valores fundamentais, filosofia, tecnologias e competências essenciais e comportamento da organização; os produtos e serviços; e as questões sustentáveis (sociais e ambientais. Embora não seja possível dizer que a presença ou ausência desses aspectos nas missões analisadas é responsável pelo desempenho das empresas, podemos afirmar que eles estão presentes na missão organizacional das 500 "Melhores \& Maiores de 2012".

Palavras-chave: Missão organizacional. Estrutura da missão. Desempenho organizacional.

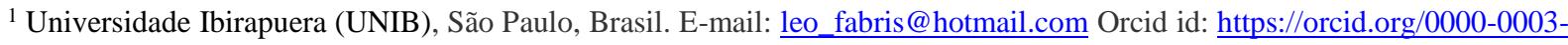
$\underline{1396-9681}$

${ }^{2}$ Faculdade de Economia, Administração e Contabilidade da Universidade de São Paulo (FEA/USP), São Paulo, Brasil. E-mail: daniel@danielmello.com Orcid id: http://lattes.cnpq.br/1147100378704009

${ }^{3}$ Faculdade de Economia, Administração e Contabilidade da Universidade de São Paulo (FEA/USP), São Paulo, Brasil. E-mail: aafischm@usp.br Orcid id: https://orcid.org/0000-0003-4344-9919

${ }^{4}$ Faculdade de Economia, Administração e Contabilidade da Universidade de São Paulo (FEA/USP), São Paulo, Brasil. E-mail: quishida@usp.br Orcid id: https://orcid.org/0000-0003-0435-559X

5 Faculdades Metropolitanas Unidas (FMU), São Paulo, Brasil. E-mail: marcuszittei@zittei.com.br Orcid id: http://orcid.org/0000-0001-8398-6941
} 


\title{
ORGANIZATIONAL MISSION STATEMENTS OF THE BEST AND BIGGEST COMPANIES IN BRAZIL
}

\begin{abstract}
The concern with results and best practices is part of the daily routine of managers and companies; this concern also includes strategic planning. In this context, this research sought to answer the following question: what is the structure of the organizational mission of companies classified as "Best and Biggest" in Brazil? For this, we analyze the organizational mission of the 500 best ranked companies in the ranking "Best \& Biggest of 2012", published by Abril publisher. It was possible to observe that the most present aspects are the identification of self-concept and fundamental values, philosophy, technologies and essential competences and behavior of the organization; products and services; and sustainability issues (social and environmental. Although it is not possible to say that the presence or absence of these aspects in the analyzed missions is responsible for the performance of companies, we can say that they are present in the organizational mission of the 500 "Best and Biggest of 2012".
\end{abstract}

Keywords: Organizational mission statement. Structure of the mission. Organizational performance. 


\section{INTRODUÇÃO}

A globalização e as rápidas mudanças tecnológicas contribuem para criar ambientes hipercompetitivos entre as organizações e exigem das empresas ações e ferramentas que as ajudem a manter suas margens de lucro e a implementar e acompanhar suas estratégias (Ireland, Hitt \& Hoskisson, 2008).

Dentro desse contexto, a preocupação com resultados tem sido uma prática comum. Muitas pesquisas que relacionam avaliação de desempenho e estratégia foram identificadas: Kaplan e Norton (1992, 1993, 1996, 2001); Almeida, Dutra, Ferraresi e Santos (2009); Bezerra, Santos e Verhagem (2011); Antunes Júnior, Bortolaso e Verschoore (2012); Crispim e Lugoboni (2012); Fernandes e Peinado (2012); Guedes, Passos e Sampaio (2012).

Ahlstrand, Lampel e Mintzberg (2000) afirmam que a literatura sobre estratégia é muito vasta e, para Porter (2004), a ênfase dada ao planejamento estratégico nas empresas leva à proposição de que se obtêm significativos benefícios com um processo explícito de formulação do planejamento estratégico.

Para muitos autores, a base de qualquer planejamento estratégico é a missão organizacional. Declarações de missão tornam-se a base sobre a qual outras ações são construídas. Só depois de uma declaração de missão ter sido desenvolvida os objetivos e estratégias apropriadas podem ser desenvolvidos (David, 1989; Klemm, Luffman \& Sanderson, 1991; Ireland \& Hitt, 1992; Bart, 1997a; Bartkus, Glassman \& McAfee, 2000).

Klemm, Luffman e Sanderson (1991) afirmam que o propósito das missões organizacionais pode ser dividido em dois pontos: a) está diretamente relacionado com relações públicas; b) relaciona-se com o direcionamento das pessoas dentro da organização.

As declarações de missão podem ajudar a focar a organização no que realmente é importante, bem como a integrar suas partes interessadas (Ireland \& Hitt, 1992). Portanto, poderíamos afirmar que uma boa missão pode ajudar a empresa a atingir melhores resultados.

Em paralelo, no Brasil e no mundo todo foram criados diversos periódicos e bancos de dados eletrônicos que congregam e divulgam informações setoriais ou generalistas sobre as empresas. No Brasil, a publicação "Melhores \& Maiores" 
da Revista Exame, da Editora Abril, é um entre os exemplos disponíveis; há mais de 30 anos, divulga a seleção das maiores empresas do Brasil, cuja avaliação é baseada nos indicadores extraídos das demonstrações contábeis fornecidas pelas empresas, de acordo com Antunes, Corrar e Kato (2004). Os autores ainda informam que, a partir de 1995, a responsabilidade pela elaboração desse trabalho foi transferida para a Fundação Instituto de Pesquisas Contábeis, Atuariais e Financeiras da FEA/USP (FIPECAFI).

Levando em consideração a importância da missão para o planejamento estratégico e tendo como base o ranking das "Melhores \& Maiores de 2012", esta pesquisa busca identificar como é a missão das empresas classificadas como "Melhores e Maiores" no Brasil. Busca também responder ao seguinte questionamento: qual a estrutura da missão organizacional das empresas classificadas como "Melhores e Maiores" no Brasil?

Esta pesquisa torna-se importante por buscar apresentar se as empresas que apresentaram melhor desempenho no ano de 2012 possuem alguma similaridade em suas missões organizacionais. Embora não se busque identificar uma correlação entre missão organizacional e resultados, a evidência de algumas estruturas na missão organizacional pode conduzir à interpretação de que o desenvolvimento correto de uma missão organizacional pode gerar melhores resultados.

\section{REFERENCIAL TEÓRICO}

\subsection{DEFINIÇÃO DE MISSÃO ORGANIZACIONAL}

Peter Drucker, em 1973, afirmou que uma empresa não era definida pelo seu nome ou contrato social, e sim por sua missão empresarial, e que somente uma clara definição da missão e dos propósitos da organização possibilita objetivos de negócio claros e realistas (David, 1989).

Embora Drucker tenha exposto a importância da missão organizacional há algumas décadas, ainda não há uma definição comum entre autores sobre o que é essa missão organizacional. Diversas são as definições apresentadas na literatura, o que leva a confusões nos níveis teórico e prático (Khalifa, 2012; Strong, 1997; Klemm, Luffman \& Sanderson, 1991). 
O estudo de Khalifa (2012) apresenta um quadro com vários autores e suas definições da declaração de missão. O Quadro 1 é uma tradução e adaptação desse quadro, incluindo também outros autores e a definição do próprio Khalifa, apresentada em seu estudo.

\begin{tabular}{|c|c|}
\hline AUTOR & DEFINIÇÃO \\
\hline $\begin{array}{l}\text { Pearce e David } \\
(1987, \text { p. 109) }\end{array}$ & $\begin{array}{l}\text { "É uma declaração duradoura de propósito que revela o produto ou serviço, } \\
\text { mercados, clientes e filosofia de uma organização. Quando preparada como } \\
\text { um documento formal da organização, uma declaração de missão pode ser } \\
\text { apresentada sob um labirinto de rótulos, incluindo a 'declaração de credo', } \\
\text { 'declaração de propósito', 'declaração de filosofia' ou uma declaração de } \\
\text { 'definição do negócio'." }\end{array}$ \\
\hline $\begin{array}{l}\text { Klemm, Luffman e } \\
\text { Sanderson (1991, } \\
\text { p. } 74)\end{array}$ & $\begin{array}{l}\text { "Não existe uma definição única para a declaração de missão; as empresas } \\
\text { utilizam uma variedade de declarações sob diferentes títulos que podem ser } \\
\text { expressas em uma frase ou ocupar várias páginas. Exemplos de } \\
\text { terminologias utilizadas são as seguintes: missão; declaração corporativa; } \\
\text { finalidades e valores; propósito; princípios; objetivos; metas; } \\
\text { responsabilidades e obrigações." }\end{array}$ \\
\hline $\begin{array}{l}\text { Ireland e Hitt } \\
(1992, \text { p. } 35)\end{array}$ & $\begin{array}{l}\text { "Uma declaração de missão eficaz descreve o propósito único e fundamental } \\
\text { da empresa. Uma parte importante dessa descrição indica como uma } \\
\text { empresa é única no seu âmbito de operações, e suas ofertas de produtos ou } \\
\text { serviços." }\end{array}$ \\
\hline Drucker (1994) & A missão explicita o papel fundamental da empresa na sociedade. \\
\hline $\begin{array}{l}\text { Rarick e Vitton } \\
(1995, \text { p. } 11)\end{array}$ & $\begin{array}{l}\text { "O que a declaração de missão deve dizer ainda está aberto para debate. } \\
\text { Para algumas das empresas pesquisadas, é apenas um local para ressaltar } \\
\text { os valores organizacionais. Para outras, é um esquema simples de quem- } \\
\text { somos, o que-nós-fazemos e para-onde-estamos-direcionados. Para outro } \\
\text { grupo, são algumas palavras sobre a visão." }\end{array}$ \\
\hline Bart $(1997$, p. 9) & $\begin{array}{l}\text { "Um documento formal escrito projetado para capturar e transmitir o } \\
\text { propósito único e duradouro de uma empresa. Ele deve responder a algumas } \\
\text { perguntas básicas, ainda que críticas, como 'qual é o nosso objetivo?' e 'por } \\
\text { que a nossa organização existe?'." }\end{array}$ \\
\hline $\begin{array}{l}\text { Leuthesser e Kohli } \\
(1997, \text { p. 59) }\end{array}$ & $\begin{array}{l}\text { "Outros pesquisadores já haviam notado que as declarações de missão - } \\
\text { diversamente referidas como declarações de propósito, declaração de } \\
\text { valores, metas e estratégias, credo corporativo, filosofia empresarial eassim } \\
\text { por diante - são estruturadas em uma variedade de maneiras. Definida de } \\
\text { forma muito ampla aqui, a expressão 'declaração de missão' deve ser } \\
\text { considerada como equivalente a inúmeras outras descrições que podem ser } \\
\text { usadas para se referir aos elementos comumente encontrados em uma } \\
\text { declaração de missão." }\end{array}$ \\
\hline $\begin{array}{l}\text { Strong }(1997, \mathrm{p} . \\
\text { 269) }\end{array}$ & $\begin{array}{l}\text { "A declaração de missão é uma definição clara da missão e do propósito da } \\
\text { organização, e pode ser referida como a declaração do credo organizacional, } \\
\text { a declaração de propósito, a declaração de princípios gerais, a declaração de } \\
\text { intenção corporativa ou a declaração de visão." }\end{array}$ \\
\hline $\begin{array}{l}\text { Ackoff (1999, p. } 83 \\
\text { apud Khalifa, 2012) }\end{array}$ & $\begin{array}{l}\text { "A declaração de missão afirma a razão de ser da organização, de seus fins } \\
\text { últimos, seus ideais." }\end{array}$ \\
\hline $\begin{array}{l}\text { Bartkus, Glassman } \\
\text { e McAfee }(2000, \mathrm{p} \text {. } \\
\text { 28) }\end{array}$ & $\begin{array}{l}\text { "As melhores declarações de missão simplesmente definem o negócio da } \\
\text { empresa e sugerem uma meta para o futuro." }\end{array}$ \\
\hline $\begin{array}{l}\text { Krattenmaker } \\
(2002, \text { p. 3) }\end{array}$ & $\begin{array}{l}\text { "A declaração de missão deve descrever os objetivos fundamentais do } \\
\text { negócio e deve incluir aquilo a que as pessoas se referem variavelmente } \\
\text { como princípios orientadores, credos e filosofias corporativas." }\end{array}$ \\
\hline $\begin{array}{l}\text { David e David } \\
(2003, \text { p. } 11)\end{array}$ & $\begin{array}{l}\text { "Existem inúmeras definições formais do que uma declaração de missão é, } \\
\text { mas a maioria delas indica que ela deve combinar uma declaração de } \\
\text { propósito para a organização com alguma forma de visão aspiracional para } \\
\text { o seu futuro, todos apresentados da forma mais sucinta possível." }\end{array}$ \\
\hline
\end{tabular}




\begin{tabular}{|c|c|}
\hline & $\begin{array}{r}\text { Continua } \\
\text { Continuação }\end{array}$ \\
\hline AUTOR & DEFINIÇÃO \\
\hline $\begin{array}{l}\text { Cardona e Rey } \\
(2006, \text { p. } 165)\end{array}$ & $\begin{array}{l}\text { "A missão de uma empresa deve ser uma contribuição que caracteriza a } \\
\text { identidade da empresa." }\end{array}$ \\
\hline $\begin{array}{l}\text { Blanchard ( } 2007, \\
\text { p. } 19 \text { apud Khalifa, } \\
\text { 2012) }\end{array}$ & $\begin{array}{l}\text { "A declaração de propósito não é a mesma coisa que a definição do negócio, } \\
\text { mas uma missão pode definir o negócio e seu papel nele, sob a forma de } \\
\text { valor único ou contribuição que se quer fazer." }\end{array}$ \\
\hline $\begin{array}{l}\text { Collis e Rukstad } \\
(2008, \text { p. } 85)\end{array}$ & $\begin{array}{l}\text { "A declaração de missão explicita a motivação subjacente para estar no } \\
\text { negócio, em primeiro lugar - a contribuição para a sociedade que a empresa } \\
\text { deseja construir." }\end{array}$ \\
\hline $\begin{array}{l}\text { Williams (2008, p. } \\
96)\end{array}$ & $\begin{array}{l}\text { "'A declaração de missão diz duas coisas sobre uma empresa: quem é e o } \\
\text { que ela faz' (Falsey, 1989, p. 3). Outros oferecem uma definição semelhante } \\
\text { [y] Além de transmitir a natureza de uma empresa e sua razão de ser, essa } \\
\text { declaração pode também destacar para onde uma empresa é dirigida, como } \\
\text { pretende chegar lá, quais são suas prioridades, valores e crenças, e como é } \\
\text { diferenciada." }\end{array}$ \\
\hline $\begin{array}{l}\text { Caruana, Pitt e } \\
\text { Sattari }(2011, \text { p. } \\
\text { 284) }\end{array}$ & $\begin{array}{l}\text { "A missão foi definida como uma breve declaração formal, por escrito, da } \\
\text { finalidade de uma organização, que deve orientar suas ações, explicitar seu } \\
\text { objetivo geral, proporcionar um senso de direção e orientar a tomada de } \\
\text { decisão." }\end{array}$ \\
\hline $\begin{array}{l}\text { Khalifa }(2012, \text { p. } \\
242)\end{array}$ & $\begin{array}{l}\text { "Consequentemente, uma nova definição de missão é proposta como um } \\
\text { compromisso firme para criar um valor ou resultado significativo em serviço } \\
\text { de uma causa justa - uma causa que os membros da organização admirem } \\
\text { e na qual estejam dispostos a depositar a sua atenção e energia em sua } \\
\text { busca." }\end{array}$ \\
\hline
\end{tabular}

\section{Quadro 1: Definições de missão organizacional}

Fonte: Traduzido e adaptado de Khalifa (2012)

\subsection{ESTRUTURA DA MISSÃO ORGANIZACIONAL}

Os primeiros estudos que contemplaram a estrutura da missão organizacional datam da década de 1980. David e Pearce (1987), em um dos primeiros estudos sobre a estrutura da missão organizacional, definiram os oito principais componentes da missão organizacional: a) Definição de clientes e mercado-alvo; b) Definição dos produtos ou serviços oferecidos; c) Definição do domínio geográfico; d) Definição das tecnologias essenciais; e) Expressão do compromisso com a sobrevivência, crescimento e lucratividade; f) Declaração dos elementos-chave na filosofia da organização; g) Identificação do autoconceito; h) Definição da imagem pública desejada. Evoluindo em suas pesquisas e buscando esclarecer cada um dos aspectos considerados na missão, David (1989) acrescenta um componente e os explica: 1- Clientes: quem são os clientes da empresa? 2- Produtos ou serviços: quais são os principais produtos ou serviços da empresa? 3- Localização: onde a empresa pretende competir? 4- Tecnologia: qual é a tecnologia essencial da empresa? 5- Preocupação com sobrevivência: qual é o compromisso da empresa com seus objetivos econômicos? 6- Filosofia: quais são 
as crenças básicas, valores, aspirações e prioridades filosóficas da empresa? 7Autoconceito: quais são os principais pontos fortes e vantagens competitivas? 8Preocupação com a imagem pública: quais são as responsabilidades públicas e que imagem pública é desejada? 9- Preocupação com os funcionários: qual é a atitude da empresa com relação aos seus funcionários?

Após David, vários outros autores estudaram a estrutura das missões organizacionais, assim como ele mesmo aprofundou-se nesse estudo.

Buscando consolidar os principais estudos realizados no mundo, após analisar os trabalhos de David e Pearce (1987); David (1989); Campbell e Yeung (1991); Bart (1997a, 1997b); Humphreys e Orr (2001); David e Peyrefitte (2006); Drori, Landau e Sheaffer (2008); King, Case e Premo (2010, 2011, 2012) e Darbi (2012), foi possível elaborar o Quadro 2, o qual relaciona autores e aspectos considerados na missão organizacional.

\begin{tabular}{|c|c|c|c|c|c|c|c|c|c|c|}
\hline Aspectos presentes/Autor e ano & 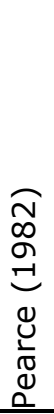 & 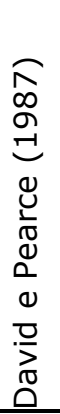 & 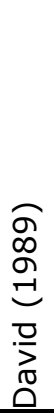 & 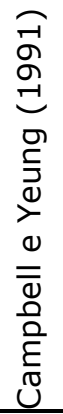 & 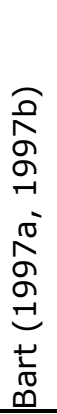 & 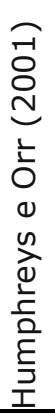 & 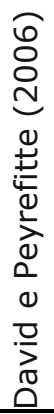 & 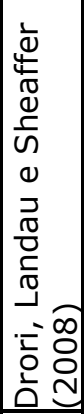 & 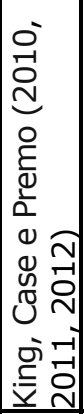 & 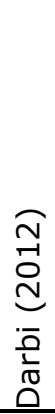 \\
\hline Proposição do negócio & & & & $\mathrm{X}$ & $\mathrm{X}$ & $\mathrm{X}$ & & & & $\mathrm{X}$ \\
\hline Clientes e mercado-alvo & $\mathrm{X}$ & $\mathrm{X}$ & $\mathrm{X}$ & & $\mathrm{X}$ & $\mathrm{X}$ & $\mathrm{X}$ & $\mathrm{X}$ & $\mathrm{X}$ & $\mathrm{X}$ \\
\hline Produtos ou serviços oferecidos & $\mathrm{X}$ & $\mathrm{X}$ & $\mathrm{X}$ & & $\mathrm{X}$ & $\mathrm{X}$ & $\mathrm{X}$ & $\mathrm{X}$ & $\mathrm{X}$ & $\mathrm{X}$ \\
\hline Definição do domínio geográfico & $\mathrm{X}$ & $\mathrm{X}$ & $\mathrm{X}$ & & $\mathrm{X}$ & $\mathrm{X}$ & $\mathrm{X}$ & $\mathrm{X}$ & $\mathrm{X}$ & $\mathrm{X}$ \\
\hline Tecnologias e competências essenciais & $\mathrm{X}$ & $\mathrm{X}$ & $\mathrm{X}$ & & $\mathrm{X}$ & $\mathrm{X}$ & $\mathrm{X}$ & $\mathrm{X}$ & $x$ & $\mathrm{X}$ \\
\hline $\begin{array}{l}\text { Compromisso com metas, sobrevivência, } \\
\text { crescimento e lucratividade }\end{array}$ & $\mathrm{X}$ & $x$ & $\mathrm{X}$ & & $x$ & $x$ & $\mathrm{X}$ & $\mathrm{X}$ & $X$ & $x$ \\
\hline $\begin{array}{l}\text { Identificação de autoconceito e valores } \\
\text { fundamentais, filosofia e comportamento da } \\
\text { organização }\end{array}$ & $\mathrm{x}$ & $\mathrm{X}$ & $\mathrm{x}$ & $\mathrm{X}$ & $X$ & $\mathrm{X}$ & $\mathrm{x}$ & $\mathrm{X}$ & $\mathrm{X}$ & $\mathrm{X}$ \\
\hline Imagem pública desejada & $\mathrm{X}$ & $X$ & $\mathrm{X}$ & & $X$ & $\mathrm{X}$ & $\mathrm{X}$ & & & \\
\hline Acionistas & & & & & $\mathrm{X}$ & & & & $\mathrm{X}$ & $\mathrm{X}$ \\
\hline Empregados & & & $\mathrm{X}$ & $\mathrm{X}$ & $\mathrm{X}$ & $\mathrm{X}$ & $\mathrm{X}$ & $\mathrm{X}$ & $\mathrm{X}$ & $\mathrm{X}$ \\
\hline Concorrentes & & & & & & & & & $\mathrm{X}$ & \\
\hline Fornecedores & & & & & $\mathrm{X}$ & & & $\mathrm{X}$ & $\mathrm{X}$ & \\
\hline Governo e legislação & & & & & & & & & $\mathrm{X}$ & \\
\hline Qualidade & & & & & & $\mathrm{X}$ & & $\mathrm{X}$ & $\mathrm{X}$ & \\
\hline Meio ambiente & & & & & & & & & $\mathrm{X}$ & \\
\hline Inovação & & & & & & & & & $\mathrm{X}$ & \\
\hline Estratégia competitiva & & & & $\mathrm{X}$ & $\mathrm{X}$ & & & & & \\
\hline Objetivos não financeiros & & & & & $X$ & & & & & \\
\hline
\end{tabular}

Quadro 2: Principais estudos sobre missão e aspectos considerados na estrutura da missão

Fonte: Elaborado pelos autores 
Com o intuito de operacionalizar este estudo, consideraram-se os seguintes aspectos: a) Aspectos relacionados à identificação de autoconceito e valores fundamentais, filosofia e comportamento da organização; b) Aspectos relacionados a clientes e mercado-alvo; c) Aspectos relacionados aos produtos ou serviços oferecidos; d) Aspectos relacionados à definição do domínio geográfico; e) Aspectos relacionados ao compromisso com metas, sobrevivência, crescimento e lucratividade; f) Aspectos relacionados aos empregados; g) Aspectos relacionados à imagem pública desejada; h) Aspectos relacionados à proposição do negócio; i) Aspectos relacionados aos stakeholders (fornecedores, concorrentes, acionistas, governo etc.); j) Aspectos relacionados a questões sustentáveis (sociais e ambientais).

Embora nenhum autor tenha abordado as questões sustentáveis (sociais e ambientais) de forma direta, acredita-se que, por uma questão de contextualização principalmente temporal, o aspecto relacionado às questões sociais e ambientais deve ser considerado.

\subsection{A RELAÇÃO ENTRE MISSÃO ORGANIZACIONAL E ESTRATÉGIA ORGANIZACIONAL}

As definições de missão são vastas, assim como seus propósitos de existência. Caruana, Pitt e Sattari (2011) lembram que Jones (1960) verificou o efeito da declaração de missão nas tomadas de decisões corporativas, na responsabilidade da organização com a comunidade e nas metas corporativas. Com isso, Caruana, Pitt e Sattari (2011) demonstram que as declarações de missão recebem atenção da literatura de gestão estratégica há anos.

Klemm, Luffman e Sanderson (1991) apontam que as declarações de missão emergiram como uma das principais ferramentas de gestão estratégica e indicam alguns de seus usos estratégicos: fornecem aos gerentes uma direção comum que transcende as necessidades individuais, departamentais e transitórias; permitem a um novo líder afirmar sua autoridade sobre a organização para levála para uma nova direção; podem gerar novas ideias em seu processo de formulação e desafiar antigas; promovem uma sensação de expectativas compartilhadas entre todos os níveis de funcionários, sendo uma parte essencial 
na construção da cultura da empresa; comunicam uma imagem pública a grupos importantes fora da empresa.

Os principais públicos de uma declaração de missão são os gestores, os funcionários, os clientes e as comunidades onde as empresas atuam (Williams, 2008), portanto podemos distinguir os propósitos de uma missão em internos e externos. Nos estudos de Klemm, Luffman e Sanderson (1991), são apresentadas duas visões de propósito de uma missão: uma voltada às relações públicas (externa) e outra voltada à motivação dos funcionários na empresa (interna); eles apontam também uma terceira visão, que seria de afirmação da liderança. As conclusões são de que a missão é vista por gestores como mais importante internamente do que externamente.

Caruana, Pitt e Sattari (2011) incluem nos propósitos externos a utilização como ferramenta de marketing, articulando a identidade da organização e determinando sua escolha de atividades. Internamente, as declarações de missão atuariam para esclarecer a filosofia e a intenção da organização para seus empregados.

Neste estudo serão considerados tanto os propósitos internos quanto os externos das declarações de missões organizacionais, separando-se sempre que possível os públicos-alvo atingidos.

\subsection{MISSÃO E DESEMPENHO ORGANIZACIONAL}

Estudos divergem quanto à relação entre as declarações de missão e o desempenho de uma empresa. Bart e Baetz (1998), em seu estudo sobre o tema, citam alguns desses estudos. Apesar da divergência, diversos autores identificam benefícios de desempenho em empresas que possuem declarações de missão estabelecidas.

Os benefícios normalmente são comportamentais ou financeiros, sendo os comportamentais uma maior motivação dos funcionários, a melhoria da liderança e o sentimento de pertencimento, apontados anteriormente, e os financeiros, 0 foco maior da empresa e a utilização de recursos de forma mais consciente (Bart \& Baetz, 1998). 
Segundo Bart e Baetz (1998), as declarações de missão que possuem em seu conteúdo os valores e as crenças da empresa e o propósito da organização bem definidos, que não incluem objetivos financeiros e que são relativamente curtas estão correlacionadas positivamente com melhor desempenho.

\subsection{ESTUDOS CORRELATOS}

Baetz e Bart (1996), ao estudarem 135 organizações do Canadá, chegaram à conclusão de que a declaração típica de missão das empresas canadenses contém essencialmente apenas um objetivo financeiro (ou nenhum), um ou dois objetivos não financeiros, um valor/crença/declaração filosófica, a definição de sucesso da organização, a prioridade número um da organização, uma definição da estratégia da organização (ou seja, uma definição de produtos específicos, mercados específicos) e referência a uma das partes interessadas (normalmente o cliente).

Bart (1997b), estudando a missão organizacional de 44 empresas industriais, descreveu a seguinte ordem de frequência dos componentes da missão: 1- Propósito de existir; 2-Valores; 3- Competência distintiva; 4- Posição competitiva desejada; 5- Identificação das partes interessadas; 6- Objetivos gerais da empresa; 7- Grandes objetivos da empresa; 8- Preocupação com os clientes; 9- Preocupação com os funcionários; 10- Preocupação com os acionistas.

James e Huisman (2009), analisando a missão organizacional de 14 instituições de ensino superior, observam que algumas instituições usam poucos aspectos, que alguns aspectos são muito utilizados e que não há duas instituições com exatamente a mesma configuração de aspectos. A maioria das instituições expressa um compromisso com seus alunos (clientes), com pesquisa, com bolsas de estudos e com o país onde atuam.

Em trabalhos que compararam as missões de empresas pelo mundo, King, Case e Premo (2011) analisaram a estrutura da missão organizacional das 25 maiores empresas dos EUA, da Austrália, do Canadá e da Grã-Bretanha.

Evidenciou-se que o cliente é o stakeholder mais presente na missão organizacional desses países. Isso também ocorreu quando King, Case e Premo (2012) compararam as missões das 25 maiores empresas dos Estados Unidos, da França, da Alemanha, do Japão e da China. 
King, Case e Premo (2011) verificaram também que as empresas dos quatro países percebem que, ao fornecer um produto ou serviço de qualidade, proporcionam valor aos seus clientes e deixam isso claro em sua missão. Além disso, as operações éticas são importantes para as empresas dos EUA, da Austrália e do Canadá, o que é evidenciado pelo fato de que a ética é o segundo ou terceiro objetivo mais incluído nas missões desses países. É interessante notar que, de acordo com os autores, os Estados Unidos foram o único país dos quatro onde a preocupação com o meio ambiente não foi uma das três principais metas ou objetivos. Em outro estudo, King, Case e Premo (2012) ressaltam que o objetivo de realizar operações comerciais em uma base global (mercado de atuação) é, em média, o objetivo mais frequente entre os cinco países analisados.

Moin, Ali e Khan (2012), analisando a estrutura da missão de 21 bancos privados do Paquistão, concluíram que os aspectos mais presentes são os clientes, a sobrevivência, o crescimento e a lucratividade, bem como preocupações com produtos ou serviços. Menos foco é dado para o mercado, a tecnologia, os colaboradores e o autoconceito.

Também foi possível encontrar trabalhos que estudaram a estrutura das missões organizacionais brasileiras. Silva, Ferreira Jr. e Castro (2006) analisaram a missão organizacional de nove instituições financeiras e observaram que, de modo geral, elas abordavam poucos elementos em suas missões, consideradas pelos autores como incompletas.

Forte e Pereira (2010), analisando a aplicação e a estrutura da missão em 17 instituições de ensino no Ceará, observaram que a missão, tida por muitos autores como ponto de partida do planejamento corporativo, não vem sendo utilizada como função de base que auxilia as decisões estratégicas. Também observaram que o aspecto mais presente na estrutura está relacionado aos clientes, seguido das definições de negócio, dos valores, da tecnologia, do domínio geográfico e, por fim, dos stakeholders.

Analisando a estrutura das missões de 140 empresas brasileiras listadas na Bolsa de Valores de São Paulo (BOVESPA) e se apoiando na proposta de estrutura de missão organizacional de Pearce (1982), Mussoi, Lunkes e Silva (2011) chegaram à seguinte classificação: 1- Principais clientes e mercados (96\%); 2- Preocupação com a imagem pública (94\%); 3- Sobrevivência, 
crescimento ou lucratividade (58\%); 4- Valores e filosofia corporativa (56\%); 5- Produtos ou serviços (44\%); 6- Competência própria/distintiva (30\%); 7- Domínio geográfico (15\%); 8- Tecnologia (7\%).

É possível observar que o aspecto de clientes e mercado é o mais presente nas missões analisadas, seguido pela preocupação com a imagem pública e por sobrevivência, crescimento ou lucratividade. Tecnologia e domínio geográfico são os aspectos menos evidenciados pelo estudo.

Analisando a estrutura completa da missão, Mussoi, Lunkes e Silva (2011) se basearam no percentual de menção aos aspectos da missão para formar o seguinte ranking: 1- Ênfase nos clientes (52\%); 2- Produtos e serviços (44\%); 3- Contexto, setor econômico ou mercado de atuação (44\%); 4- Preocupação com a qualidade (39\%); 5- Retorno ao acionista (33\%); 6- Filosofia e valores corporativos (33\%); 7- Menção aos colaboradores (32\%); 8- Responsabilidade social (30\%); 9- Conceito próprio/distintivo da empresa (30\%); 10- Rentabilidade/crescimento/sobrevivência (25\%); 11- Compromisso com o desenvolvimento (sustentável/econômico/social) (23\%); 12- Responsabilidade ambiental (20\%); 13- Local de atuação (21\%); 14- Menção aos fornecedores $(10 \%) ; 15-$ Tecnologia utilizada (7\%).

King, Case e Premo (2011) afirmam que as mudanças no ambiente de negócios ocorrem de forma contínua e que será interessante ver como as declarações de missão evoluirão nos próximos cinco a dez anos.

\section{METODOLOGIA}

Este estudo tem o objetivo de analisar a estrutura de declarações de missão de empresas brasileiras. Para atingir esse objetivo foi desenvolvida uma pesquisa documental. Martins e Theophilo (2009, p.87) apontam que a "estratégia de pesquisa documental é característica dos estudos que utilizam documentos como fonte de dados, informações e evidências". Os autores indicam que os documentos podem ser de vários tipos, escritos ou não. Nesta pesquisa foram utilizados os dados contidos nos websites das empresas pesquisadas.

Foi feita a análise de conteúdo das declarações de missão. Segundo Bardin (1977, p.125), a "análise de conteúdo é um conjunto de técnicas de análise de comunicações, que utiliza procedimentos sistemáticos e objetivos de descrição do 
conteúdo das mensagens". Martins e Theophilo (2009, p.88) indicam como um dos principais usos da análise de conteúdo "construir e aplicar padrões de comunicação".

Após a coleta das declarações de missão, foi feita a análise de frases e palavras contidas nas missões para classificá-las nas categorias estabelecidas no referencial teórico exposto anteriormente.

Após a categorização, foi feita análise quantitativa dos dados, gerando dados descritivos em seus resultados. Para as empresas foi atribuído o valor 1 (um) para cada categoria que estivesse retratada em sua missão e o valor 0 (zero) para as categorias não explícitas na missão.

\subsection{AMOSTRA}

A amostra da pesquisa foi feita com base na pesquisa "Melhores \& Maiores de 2012", publicação da Revista Exame, da editora Abril, em parceria com a Fundação Instituto de Pesquisas Contábeis, Atuariais e Financeiras (FIPECAFI). A publicação estabelece um ranking das 1000 maiores empresas do Brasil pelo critério do desempenho em vendas, em dólares.

Para este estudo foram selecionadas as 500 primeiras empresas do ranking. O passo seguinte foi identificar os websites dessas empresas e buscar suas declarações de missão. Das 500 empresas, 43 não disponibilizam a declaração de missão em seus websites ou não têm essa informação em local de fácil acesso, totalizando 457 empresas analisadas, o que corresponde a 91,4\% das 500 empresas classificadas como "Melhores \& Maiores de 2012".

\section{ANÁLISE DOS RESULTADOS}

Com o objetivo de identificar a estrutura da missão organizacional das 500 empresas classificadas como "Melhores e Maiores" no Brasil, foram feitas análises das missões organizacionais conforme o Quadro 3, que mostra os critérios utilizados e coloca exemplos de missões que evidenciam as categorias estudadas. É possível observar nos exemplos que uma missão organizacional pode conter mais 
de um aspecto em sua estrutura, mas no Quadro 3 destacamos (sublinhamos) apenas o trecho que expressa de forma clara o aspecto exemplificado. 


\begin{tabular}{|c|c|c|}
\hline Aspectos & O que foi analisado & Exemplos \\
\hline $\begin{array}{l}\text { a) Identificação de autoconceito } \\
\text { e valores fundamentais, } \\
\text { filosofia, tecnologias e } \\
\text { competências essenciais e } \\
\text { comportamento da organização }\end{array}$ & $\begin{array}{c}\text { Se a missão descreve valores } \\
\text { organizacionais, características, } \\
\text { posicionamento filosófico, tecnologia ou } \\
\text { competência indispensável ou } \\
\text { comportamento esperado da empresa }\end{array}$ & Gol - "Aproximar pessoas com segurança e inteligência" (53) \\
\hline b) Clientes e mercado-alvo & $\begin{array}{l}\text { Se a missão descreve características dos } \\
\text { clientes que a empresa quer atender }\end{array}$ & $\begin{array}{l}\text { Sap - "Nossa missão é ajudar as empresas de todos os portes e } \\
\text { setores a se tornarem empresas mais bem administradas" (407) }\end{array}$ \\
\hline $\begin{array}{l}\text { c) Produtos ou serviços } \\
\text { oferecidos }\end{array}$ & $\begin{array}{l}\text { Se a missão descreve os produtos ou } \\
\text { serviços que a empresa oferece }\end{array}$ & $\begin{array}{c}\text { Golden Cross - "Prover soluções em saúde, proporcionando satisfação } \\
\text { e segurança aos nossos clientes" (295) }\end{array}$ \\
\hline $\begin{array}{l}\text { e) Compromisso com } \\
\text { sobrevivência, crescimento e } \\
\text { lucratividade }\end{array}$ & $\begin{array}{c}\text { Se a missão descreve objetivos, metas, } \\
\text { questões financeiras, competitividade, lucro } \\
\text { etc. }\end{array}$ & $\begin{array}{c}\text { Gafisa - "Estabelecer-se como companhia líder no desenvolvimento } \\
\text { residencial no Brasil em termos de vendas, rentabilidade e qualidade } \\
\text { do produto" (431) }\end{array}$ \\
\hline f) Empregados & $\begin{array}{c}\text { Se a missão descreve seu posicionamento } \\
\text { com relação ao tratamento ou à importância } \\
\text { dos empregados }\end{array}$ & $\begin{array}{c}\text { Araújo - "Encantar e satisfazer as necessidades de nossos clientes, } \\
\text { criar valor para os acionistas, zelar pela realização de seus } \\
\text { colaboradores e pelo bem estar da sociedade" (473) }\end{array}$ \\
\hline g) Imagem pública desejada & $\begin{array}{l}\text { Se a missão deixa claro como a empresa } \\
\text { quer ser vista pelo público de modo geral }\end{array}$ & $\begin{array}{c}\text { Veracel - "A Veracel quer ser uma referência mundial em } \\
\text { sustentabilidade e destacar-se como uma empresa ambientalmente } \\
\text { correta, socialmente justa e economicamente viável" (499) }\end{array}$ \\
\hline $\begin{array}{l}\text { j) Questões sustentáveis } \\
\text { (sociais e ambientais) }\end{array}$ & $\begin{array}{c}\text { Se a missão da empresa trata de questões } \\
\text { relacionadas à preocupação com a } \\
\text { sustentabilidade, a sociedade e o meio } \\
\text { ambiente }\end{array}$ & $\begin{array}{c}\text { Petróleo Sabbá - "Atuar de forma segura e rentável, com } \\
\text { responsabilidade social e ambiental, nos mercados nacional e } \\
\text { internacional, fornecendo produtos e serviços adequados às } \\
\text { necessidades dos clientes e contribuindo para o desenvolvimento do } \\
\text { Brasil e dos países onde atua" (173) } \\
\end{array}$ \\
\hline
\end{tabular}

\section{Quadro 3: Critérios de avaliação e exemplos de missões avaliadas}

Fonte: Análise dos autores 
Para a apresentação dos resultados utilizou-se a estatística descritiva por meio de tabelas. Os dados das 500 empresas foram consolidados na Tabela 1. Após a análise de estrutura das missões, os critérios foram classificados em ordem decrescente, mostrando assim seus aspectos mais relevantes.

\section{Tabela 1: Evidenciação da estrutura das missões organizacionais}

\begin{tabular}{|c|c|c|c|c|}
\hline \multirow{3}{*}{ Aspectos da estrutura das missões } & \multicolumn{4}{|c|}{ Valores } \\
\hline & \multicolumn{2}{|c|}{1} & \multicolumn{2}{|c|}{$\mathbf{0}$} \\
\hline & Obs. & $\%$ & Obs. & $\%$ \\
\hline $\begin{array}{c}\text { a) Identificação de autoconceito e valores fundamentais, filosofia, } \\
\text { tecnologias e competências essenciais e comportamento da } \\
\text { organização }\end{array}$ & 321 & $70 \%$ & 136 & $30 \%$ \\
\hline c) Produtos ou serviços oferecidos & 281 & $61 \%$ & 176 & $39 \%$ \\
\hline j) Questões sustentáveis (sociais e ambientais) & 254 & $56 \%$ & 203 & $44 \%$ \\
\hline h) Proposição do negócio & 184 & $40 \%$ & 273 & $60 \%$ \\
\hline $\begin{array}{c}\text { e) Compromisso com metas, sobrevivência, crescimento e } \\
\text { lucratividade }\end{array}$ & 151 & $33 \%$ & 306 & $67 \%$ \\
\hline f) Empregados & 119 & $26 \%$ & 338 & $74 \%$ \\
\hline $\begin{array}{l}\text { i) Stakeholders (fornecedores, concorrentes, acionistas, governo } \\
\text { etc.) }\end{array}$ & 117 & $26 \%$ & 340 & $74 \%$ \\
\hline d) Definição do domínio geográfico & 103 & $23 \%$ & 354 & $77 \%$ \\
\hline g) Imagem pública desejada & 87 & $19 \%$ & 370 & $81 \%$ \\
\hline b) Clientes e mercado-alvo & 33 & $7 \%$ & 424 & $93 \%$ \\
\hline Evidenciação média & 165 & $36 \%$ & 292 & $64 \%$ \\
\hline
\end{tabular}

Fonte: Elaborado pelos autores

É possível observar que o aspecto mais abordado pelas missões organizacionais está relacionado a valores fundamentais, filosofia, tecnologia e competências essenciais, e comportamentos organizacionais desejados, presente em $70 \%$ das missões organizacionais das empresas analisadas. Embora o aspecto seja abrangente e permita diversas possibilidades de enquadramento da missão organizacional, foi nítida na análise de conteúdo a presença de termos que descrevem como a empresa pretende se comportar ou as características essenciais para suas atividades.

Nossa missão é ser a referência da distribuição moderna em cada um dos nossos mercados, trazendo para: Os nossos clientes: o melhor preço combinado com a melhor oferta comercial em cada bandeira, em cada país; Os nossos colaboradores: a possibilidade de expandir um clima de confiança e de progredir com um trabalho e uma remuneração motivadores; Os nossos acionistas: a rentabilidade de seu investimento a longo prazo e as perspectivas de crescimento de um grupo internacional e de múltiplos formatos (Carrefour, posição 23 no ranking, grifo nosso). 
A missão da Tam (posição 24 no ranking, grifo nosso) é "Ser a companhia aérea preferida das pessoas, com alegria, criatividade, respeito e responsabilidade". A da Nestlé (posição 77 no ranking, grifo nosso), "Oferecer ao consumidor brasileiro produtos reconhecidamente líderes em qualidade e valor nutritivo, que contribuam para uma alimentação mais saudável e agradável, gerando sempre oportunidades de negócios para a empresa e valor compartilhado com a sociedade brasileira".

Produtos ou serviços oferecidos são a segunda estrutura mais presente nas missões organizacionais das empresas analisadas (61\% do total). Por exemplo: "Produzir, transmitir e comercializar energia elétrica com qualidade, de forma rentável e sustentável (Chesf, posição 76 no ranking, grifo nosso); "Produzir e distribuir com responsabilidade alimentos, prioritariamente de origem láctea, confiáveis e saborosos, proporcionando retorno financeiro excepcional na busca contínua da construção de uma empresa de classe mundial, garantindo a sustentabilidade da LBR" (LBR, posição 487 no ranking, grifo nosso); "Atuar no negócio de transformação de cobre e outros metais não-ferrosos em produtos, serviços e soluções para atender as necessidades de nossos clientes" (Termomecanica, posição 496 no ranking, grifo nosso).

O terceiro aspecto mais presente nas missões organizacionais é a declaração do posicionamento sustentável, ambiental e/ou social, declarado por $56 \%$ das empresas. Conforme já destacado, as pesquisas seminais sobre missão organizacional de Pearce (1982), David e Pearce (1987), David (1989), Campbell e Yeung (1991) e Bart (1997a, 1997b) não abordam de forma direta as questões sustentáveis, sociais e/ou ambientais, embora o momento que a sociedade vive exija que esses assuntos sejam incluídos em suas estratégias e missões: "Gerar energia elétrica de qualidade, com responsabilidade social e ambiental, impulsionando o desenvolvimento econômico, turístico e tecnológico, sustentável, no Brasil e no Paraguai" (Itaipu Binacional, posição 60 no ranking, grifo nosso); "Oferecer produtos de base florestal renovável, celulose e papel, destacando-se globalmente pelo desenvolvimento de soluções inovadoras e contínua busca da excelência e sustentabilidade em nossas operações" (Suzano, posição 81 no ranking, grifo nosso); "Facilitar e ampliar o acesso à saúde, por meio de produtos, 
serviços e iniciativas, em total integração com os parceiros e colaboradores, sempre com entusiasmo, responsabilidade e respeito pelos valores da sustentabilidade" (Medley, posição 416 no ranking, grifo nosso).

De acordo com os dados da pesquisa apresentados na Tabela 1, é possível verificar que os aspectos menos presentes nas missões organizacionais são a definição do domínio geográfico (103 missões), a imagem pública desejada (87 missões) e os clientes e mercados-alvo (33 missões), com evidenciações de $23 \%$, $19 \%$ e $7 \%$, respectivamente.

A Tabela 1 também mostra que o nível de evidenciação média é de $36 \%$, deixando claro que nem todos os itens precisam ser utilizados.

As evidenciações encontradas corroboram os estudos de Bart (1997b) que destacam como aspectos mais evidenciados os itens "propósito de existir", "valores", "competência distintiva" e "posição competitiva desejada". Os achados também ratificam a presença e importância do aspecto de produtos ou serviços, que King, Case e Premo (2011) e Moin, Ali e Khan (2012) mencionam em seus estudos.

Quando os dados são comparados com estudos brasileiros, os itens definições de negócio, valores e tecnologia estão presentes de forma significativa também no trabalho de Forte e Pereira (2010).

Em relação ao aspecto de questões sustentáveis, grandes semelhanças se notam deste estudo com os achados de King, Case e Premo (2011), quando estes afirmam que apenas nos Estados Unidos esse aspecto não está claro na missão.

Mussoi, Lunkes e Silva (2011) encontraram resultados parecidos no que tange à presença de valores e filosofia corporativa, e produtos ou serviços.

Os achados apresentam divergências quando comparados com os estudos de James e Huisman (2009), Forte e Pereira (2010), Mussoi, Lunkes e Silva (2011), King, Case e Premo (2011) e Moin, Ali e Khan (2012) no que se refere ao aspecto cliente e ao grau de importância dado à preocupação com a imagem pública, evidenciado por Mussoi, Lunkes e Silva (2011). 


\section{CONCLUSÕES}

Ambientes hipercompetitivos para as organizações exigem das empresas ações e ferramentas que as ajudem a manter suas margens de lucro e a implementar e acompanhar suas estratégias. A preocupação com resultados e melhores práticas faz parte do cotidiano dos gestores e das empresas; essa preocupação inclui, também, o planejamento estratégico.

Para muitos autores, a base de qualquer planejamento estratégico é a missão organizacional. Declarações de missão tornam-se a base sobre a qual outras ações são construídas. Só depois de uma declaração de missão ter sido desenvolvida os objetivos e as estratégias apropriadas podem ser desenvolvidos (David, 1989; Klemm, Luffman \& Sanderson, 1991; Ireland \& Hitt, 1992; Bart, 1997a; Bartkus, Glassman \& McAfee, 2000).

As declarações de missão podem ajudar a focar a organização no que realmente é importante, bem como a integrar suas partes interessadas (Ireland \& Hitt, 1992). Portanto, poderíamos afirmar que uma boa missão pode ajudar as empresas a atingir melhores resultados.

Dentro desse contexto, esta pesquisa buscou responder ao seguinte questionamento: qual a estrutura da missão organizacional das empresas classificadas como "Melhores e Maiores" no Brasil? Para isso analisamos a missão organizacional das 500 empresas mais bem classificadas no ranking "Melhores \& Maiores de 2012", publicado pela editora Abril.

De acordo com os dados encontrados, é possível afirmar que, entre as estruturas possíveis, o aspecto mais presente é a identificação de autoconceito e valores fundamentais, filosofia, tecnologias e competências essenciais e comportamento da organização. Cerca de $70 \%$ das empresas possuem em sua missão evidências dessa estrutura.

Outro aspecto abordado de forma significativa é o detalhamento dos produtos e serviços que a empresa pretende oferecer, empregado por cerca de $61 \%$ das empresas. 
Um item que chama a atenção é o terceiro aspecto mais citado pelas empresas em suas missões organizacionais: questões sustentáveis (sociais e ambientais). Esse aspecto está presente em 56\% das missões organizacionais. Chama a atenção porque não é abordado com frequência na literatura e deixa claro que, por uma questão de contextualização principalmente temporal, as empresas o englobaram em suas missões e, consequentemente, em suas estratégias.

Foi possível perceber que, entre as 500 empresas mais bem posicionadas no ranking, em média apenas $36 \%$ dos aspectos foram citados, deixando claro que nem todas as empresas fazem referência à maioria dos aspectos possíveis, conforme evidenciado por trabalhos internacionais (James \& Huisman, 2009) e nacionais (Silva, Ferreira Jr. \& Castro, 2006; Forte \& Pereira, 2010; Mussoi, Lunkes \& Silva, 2011).

Esta pesquisa não permite dizer que a presença ou ausência dos aspectos em suas missões é responsável por seus faturamentos ou lucros, uma vez que muitos outros fatores podem ter interferido nesses resultados. Contudo, este estudo evidencia (e essa é sua principal contribuição) que questões como filosofias, valores, competências essenciais, produtos e serviços, assim como questões sustentáveis, ambientais e sociais, estão presentes de forma significativa nas missões organizacionais das "Melhores e Maiores". Essa informação leva ao menos à reflexão de como essas questões podem ser trabalhadas em missões e, principalmente, nas estratégias para melhorar o desempenho organizacional.

Como limitações desta pesquisa, podemos citar o fato de que a literatura não é adequada ao mercado brasileiro. A maioria dos trabalhos que discute a missão organizacional é estrangeira.

Como foi possível identificar semelhanças e divergências tanto com trabalhos empíricos nacionais quanto com os internacionais, fica a indagação com relação aos fatores que podem levar a essas divergências.

A subjetividade da análise é outra limitação, uma vez que a análise de conteúdo pode levar a diversas interpretações.

Analisando a estrutura e metodologia dos estudos realizados é possível destacar fatores de influência, como por exemplo: 1- A influência do país/região 
(Baetz \& Bart, 1996; Forte \& Pereira, 2010; Mussoi, Lunkes \& Silva, 2011; King, Case \& Premo, 2011, 2012); 2- A influência do setor de atuação (Bart, 1997b; Silva, Ferreira Jr. \& Castro, 2006; James \& Huisman, 2009; Forte \& Pereira, 2010; Moin, Ali \& Khan, 2012); e 3- Adaptações da estratégia da empresa ao longo do tempo, conforme ressaltam King, Case e Premo (2011), que afirmam que as mudanças no ambiente de negócios ocorrem de forma contínua, e que será interessante ver como as declarações de missão evoluem nos próximos cinco a dez anos.

Como sugestões para trabalhos futuros, uma comparação entre as missões organizacionais do Brasil e de outros países (inclusive segregadas por setor de atuação) permitiria compreender como as diferenças culturais podem afetar a estrutura das missões. Também seria importante analisar se o segmento em que a empresa atua pode influenciar de forma significativa a estrutura de sua missão organizacional.

\section{REFERÊNCIAS}

Almeida, M. I. R., Dutra, I. S., Ferraresi, A. A. \& Santos, S. A. (2009). Estudo sobre a análise ambiental de ameaças do plano de ações estratégicas, e seus resultados após 4 anos: o caso da implantação de incubadora tecnológica no interior do Paraná no ano de 2000. Revista Alcance, 16 (1), 8-25.

Antunes, M. T. P., Corrar, L. J. \& Kato, H. T. (2004). A Eficiência das informações divulgadas em "Maiores \& Melhores" da revista exame para a previsão de desempenho de empresas. Revista Contabilidade \& Finanças - USP, Edição Especial, 41, 50, 30.

Antunes Júnior, J. A. V., Bortolaso, I. \& Verschoore, J. R. (2012) Estratégias Cooperativas: Avaliando a gestão da estratégia em redes de pequenas e médias empresas. Revista brasileira de gestão e negócios, 14 (45), 419-437.

Baetz, M. C. \& Bart, C. K. (1996). Developing mission statements which work. Long Range Planning, 29 (4), 526-533.

Bart, C. K. (1997a). Sex, Lies, and Mission Statements. Business Horizons, 9-18.

Bart, C. K. (1997b). Industrial Firms and the Power of Mission. Industrial Marketing Management. 26, 371-383. 
Bart, C. K. \& Baetz, M. C. (1998). The relationship between mission statements and HRM performance: an exploratory study. Journal of Management Studies, $35(6), 823-853$.

Bartkus, B. Glassman, M. \& McAfee, R. B. (2000). Mission Statements: Are They Smoke and Mirrors? Business Horizons, 23-28.

Bezerra, F. A., Santos, P. S. A. \& Verhagem, J. A. (2011). Gerenciamento de resultados por meio de decisões operacionais e governança corporativa: analise das indústrias siderúrgicas e metalúrgicas brasileiras. RCO, 5 (13), 56-74.

Cardona, P. \& Rey, C. (2006). Management by missions: how to make the mission a part of management. Problems and Perspectives in Management, 15 (1), 164174.

Caruana, A., Pitt, L. F. \& Sattari, S. (2011). How readable are mission statements? An exploratory study. Corporate Communications: An International Journal, 16 (4), 282-292.

Collis, D. J. \& Rukstad, M. J. (2008). Can you say what your strategy is? Harvard Business Review, 86 (4), 82-90.

Crispim, S. F. \& Lugoboni, L. F. (2012). Modelos de Avaliação de Desempenho Organizacional nas Instituições de Ensino Superior da Região Metropolitana de São Paulo. Revista Portuguesa e Brasileira de Gestão, 11 (1), 42-54.

Darbi, W. P. K. (2012). Of Mission and Vision Statements and Their Potential Impact on Employee Behaviour and Attitudes: The Case of A Public But ProfitOriented Tertiary Institution. International Journal of Business and Social Science, 3 (14). Special edition.

David, F. R. (1989). How Companies Define Their Mission. Long Range Planning, $22(1), 90-97$.

David, F. R. \& David, F. R. (2003) It's time to redraft your mission statement. Journal of Business Strategy, 24 (1), 11-14.

David, F. \& Pearce, J. A. (1987) Corporate mission statements: The Bottom Line. Academy of Management Executive, 1 (2), 109-116.

David, F. R. \& Peyrefitte, J. (2006). A Content Analysis of the Mission Statements of United States Firms in Four Industries. International Journal of Management, $23(2)$.

Drori, I., Landau, D. \& Sheaffer, Z. (2008). Mission Statement and Performance: An Evidence of "Coming of Age". Organization Development Journal, 26 (2).

Drucker, P. F. (1994). The theory of the business, Harvard Business Review, 72 (5), 95-104. 
Fernandes, B. H. R. \& Peinado, J. (2012). Estratégia, competências e desempenho em empresas de pet shop: evidências de um levantamento em Curitiba. $R$. Adm., 47 (4), 609-623.

Forte, S. H. A. C. \& Pereira, M. S. (2010). A construção e disseminação da missão nas instituições de ensino superior no Ceará. Revista Gestão \& Tecnologia, $2(1)$.

Guedes, C. M. C., Passos, F. U. \& Sampaio, R. R. (2012). O monitoramento de desempenho está alinhado com a estratégia? Observação em frigoríficos da caprinovinocultura da Bahia, REGE, 19 (3), 411-429.

Humphreys, R. L. \& Orr, S. K. (2012). Mission Rivalry: Use and Preservation Conflicts in National Parks Policy. Public Organiz Rev, 12, 85-98.

Ireland, R.; Hitt, M. A. \& Hoskisson, R. E. (2003). Administração estratégica. 2. ed. São Paulo: Pioneira Thomson Learning.

Ireland, R. D. \& Hitt, M. A. (1992). Mission Statements: Importance, Challenge, and Recommendations for Development. Business Horizons, 35 (3), 34-42.

James, H. \& Huisman, J. (2009). Missions statements in Wales: the impact of markets and policy on congruence between institutions. Journal of Higher Education Policy and Management, 31 (1), 23-35.

Kaplan, R. S. \& Norton, D. P. (1992). The balanced scorecard: measures that drive performance. Harvard Business Review, 70 (1), 71-79.

Kaplan, R. S. \& Norton, D. P. (1993). Putting the Balanced Scorecard to Work. Harvard Business Review, 71 (5), 134-147.

Kaplan, R. S. \& Norton, D. P. (1996). Using a Balanced Scorecard as a Strategic Management System. Harvard Business Review, 74 (1), 75-85.

Kaplan, R. S. \& Norton, D. P. (2001). Transforming the balanced scorecard from performance measurement to strategic management: part I. Accounting Horizons.

Khalifa, A. S. (2012). Mission, purpose, and ambition: redefining the mission statement. Journal of Strategy and Management, 5 (3), 236-251.

King, D. L., Case, C. J. \& Premo, K. M. (2010). Current Mission Statement Emphasis: Be Ethical and go Global. Academy of Strategic Management Journal, 9 (2), 71-87.

King, D. L., Case, C. J. \& Premo, K. M. (2011). A Mission statement analysis Comparing the United States and three other English speaking countries. Academy of Strategic Management Journal, 10, Special Edition, 21-45. 
King, D. L., Case, C. J. \& Premo, K. M. (2012). An International mission statement comparison: United States, France, Germany, Japan and China. Academy of Strategic Management Journal, 11 (2), 93-119.

Klemm, M., Luffman, G \& Sanderson, S. (1991). Mission Statements: Selling Corporate Values to Employees. Long Range Planning, 24 (3), 73-78.

Krattenmaker, T. (2002). Write a mission statement that your company is willing to live. Harvard Management Communication Letter, 5 (3), 1-5.

Leuthesser, L. \& Kohli, C. (1997) Corporate identity: the role of mission statements. Business Horizons, 40 (3), 59-66.

Martins, G. d. A., \& Theóphilo, C. R. (2009). Metodologia da investigação científica para ciências sociais aplicadas. São Paulo: Atlas.

Mintzberg, H., Ahlstrand, B. \& Lampel, J. (2006). Safári de estratégia: um roteiro pela selva do planejamento estratégico. Porto Alegre: Bookman.

Moin, M. F., Ali, A. \& Khan, A. N. (2012). An Analysis of Mission Statement of Pakistani Commercial (Scheduled) banks using a Nine Points Scale approach of Fred R. David. Interdisciplinary Journal of Contemporary Research in Business, $4(2), 102-120$.

Pearce, J. (1982). The company mission as a strategic tool. Sloan Management, $23(3), 15-24$.

Pearce, J \& David, F. (1987). Corporate mission statements: The bottom line. Academy of Management Executive, 1 (2), 109-116.

Porter, M. E. (2004). Estratégia competitiva: Técnicas para análise de indústrias da concorrência. 2. ed. Rio de Janeiro: Elsevier.

Strong, S. (1997). The question we continue to ask: How do organisations define their mission? Journal of Marketing Practice: Applied Marketing Science, 3 (4), 268-283.

Williams, L. S. (2008). A Corporate Reporting Tool with a Past, Present, and Future. Journal of Business Communication, 45 (2), 94-119. 